\title{
Neutral Point Diode Clamped Multi-Level Control of DSTATCOM by Using Fuzzy Gain Scheduling PI and Fuzzy Logic Controllers
}

\author{
Ganesh Prasad Reddy \\ K. Ramesh Reddy \\ Department of Electrical and Electronics Engineering, Department of Electrical and Electronics Engineering, \\ Vasireddy Venkatadri Institute of Technology \\ Guntur, India. \\ G. Narayanamma Institute of Technology, \\ Hyderabad, India.
}

\begin{abstract}
This paper presents the three - level neutral point diode clamped inverter is used in a distribution static compensator (DSTATCOM), making use of the multi-level inverter advantages of low harmonics distortion and reduced switching losses. The pulse width modulation (PWM) inverter is employed as DSTATCOM compensating reactive power and eliminates the harmonics drawn from a non-linear load. A fuzzy gain scheduled proportional and integral (FGPI) dc voltage controller is proposed for inverter dc voltage control to improve the performances of three - levels DSTATCOM and fuzzy logic current controller is proposed to reduce harmonic supply currents for DSTATCOM. The D-Q reference frame theory is used to generate the reference compensating currents for three -level DSTATCOM. The three-level DSTATCOM with proposed control schemes is implemented in Matlab/Simulink software platform. The simulation results show that the system with proposed control schemes provides a good inverter dc voltage regulation, reduced harmonics distortion in supply current and in phase with line voltage.
\end{abstract}

\section{Key words}

DSTATCOM, fuzzy gain scheduled PI controller, fuzzy logic controller, and multilevel inverter.

\section{INTRODUCTION}

The shunt compensation for medium voltage distribution systems requires higher rating for voltage source converters (VSCs). Ratings of the semiconductor devices in a VSC are always limited; therefore for higher rated converters it is desirable to distribute the stress among the number of devices using multilevel topology [1]. Diode clamped multilevel configuration of inverter has the advantage of its simplicity and modularity over the configurations of flying capacitor multilevel inverters. Application of cascaded multilevel converters for shunt compensation of distribution systems has been described in [2-3]. The use of neutral point diode clamped inverters allows equal voltage shearing of series connected semiconductors in each phase. There are various current control methods for two-level converters [4]. Hysteresis control of power converters, based on instantaneous current errors, is widely used for the compensation of the distribution system as it has good dynamic characteristics and robustness against parameter variations and load nonlinearties [5]. A distribution static compensator (DSTATCOM) is a voltage source converter (VSC) based device. When operated in a current control mode, it can improve the quality of power by mitigating poor load power factor, eliminating harmonic content of load and balancing source currents for unbalanced loads [5-7].

The controller scheme is major role of the DSTATCOM operation and has been a subject of many researches in recent years [8-12]. According to the conventional proportional integral (PI), proportional-integral-derivative (PID) control schemes will not reach a high performance [13]. Since the dynamics of a distribution system even for a reduced mathematical model is usually non-linear, time variant and governed by strong cross-couplings of the input variables the controllers have to be designed with special care [14]. Thus, a gain scheduling controller can be used for nonlinear systems [15]. In this method, control parameters can be changed very quickly because parameter estimation is not required. It is easier to realize as compared with automatic tuning or adaptation of controller parameters. However, the transient response can be unstable because of abruptness in system parameters. Besides, it is impossible to obtain accurate linear time invariant models at variable operating points [15]. Some fuzzy gain scheduling of PI controllers have been proposed to solve such problems in power systems [15] and [16] that developed different fuzzy rules for the proportional and integral gains separately. Fuzzy logic control presents a good tool to deal with complicated, non-linear and indefinite and time-variant systems [17]. The advantages of FGPI and fuzzy logic controllers are: robustness, no need to accurate mathematical model, can work with precise inputs and can handle non-linearity.

In this paper, we presents a fuzzy gain scheduled proportional and integral and fuzzy logic controller schemes are proposed for inverter dc voltage control and harmonic currents to improve the performances neutral point diode clamped three-level DSTATCOM. The performances of the proposed control schemes are validated through the computer simulation under steady-state conditions. Details on operation, modeling, analysis, design calculations, control strategy and simulation results for DSTATCOM is presented in the subsequent sections.

\section{DESCRIPTIONS OF DSTATCOM WITH CONTROL SCHEMES}

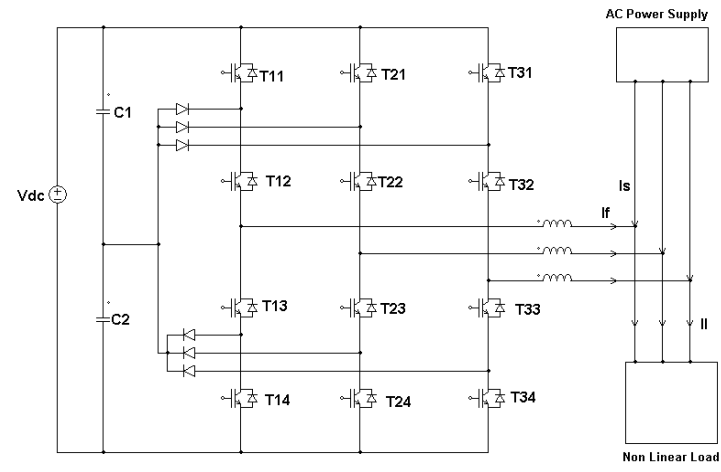

Fig. 1. Three-level dstatcom operation.

The main objective of the proposed three-level DSTATCOM is to reduce harmonic in supply currents, improve the power factor and compensate the reactive power. The structure is depicted in 
Fig. 1, describes this shunt DSTATCOM based on a three phase three-level neutral point diode clamped voltage source inverter (VSI). The diodes are used to make the connection with the point of reference $\mathrm{O}$ to obtain Midpoint voltages. In order to produce an inverter (DSTATCOM) of N levels, N-1 capacitors are required. The voltage across each capacitor is equal to $\mathrm{Vdc}$ $/(\mathrm{N}-1), \mathrm{Vdc}$ is the total voltage of the dc source. Each couple of switches (S1, S3) form a cell of commutation, the two switches are ordered in a complementary way. The inverter provides three voltage levels according to equation (1):

$V_{i o}=K_{i} \frac{V_{d c}}{2}$

(1)

Where, Vio is the phase-to-middle fictive point voltage $\mathrm{Ki}$ is the switching state variable $(\mathrm{Ki}=1,0,-1), \mathrm{Vdc}$ is the DC source voltage, and $\mathrm{I}$ is the phase index $(\mathrm{i}=\mathrm{a}, \mathrm{b}$ and $\mathrm{c})$. The three voltage values are shown in Table $1(\mathrm{Vdc} / 2,0,-\mathrm{Vdc} / 2)$.

Table 1. Obtaining three-level inverters $\mathrm{V}_{\mathrm{dc}} / 2,-\mathrm{V}_{\mathrm{dc}} / 2, \mathrm{~K}_{\mathrm{i}}$.

\begin{tabular}{|l|l|l|l|l|l|}
\hline $\mathrm{K}_{\mathrm{i}}$ & $\mathrm{T}_{\mathrm{i} 1}$ & $\mathrm{~T}_{\mathrm{i} 2}$ & $\mathrm{~T}_{\mathrm{i} 3}$ & $\mathrm{~T}_{\mathrm{i} 4}$ & $\mathrm{~V}_{\mathrm{io}}$ \\
\hline 1 & 1 & 1 & 0 & 0 & $\mathrm{~V}_{\mathrm{dc}} / 2$ \\
\hline 0 & 0 & 1 & 1 & 0 & 0 \\
\hline-1 & 0 & 0 & 1 & 1 & $-\mathrm{V}_{\mathrm{dc}} / 2$ \\
\hline
\end{tabular}

The phase to neutral point voltage $\mathrm{V}_{\text {in }}$ is linked to $\mathrm{V}_{\text {io }}$ via:

$$
V_{\text {in }}=V_{\text {io }}+V_{\text {no }}
$$

Assuming that the system is balanced, then:

$$
V_{a n}+V_{b n}+V_{c n}=0
$$

By substituting equation (3) in equation (2), then obtained equation is

$$
V_{n o}=\frac{1}{3}\left(V_{a o}+V_{b o}+V_{c o}\right)
$$

The expressions of instantaneous inverter phase output voltages are obtained by replacing equation (4) in equation (2):

$$
\left[\begin{array}{l}
V_{a n} \\
V_{b n} \\
V_{c n}
\end{array}\right]=\left[\begin{array}{ccc}
2 / 3 & -1 / 3 & -1 / 3 \\
-1 / 3 & 2 / 3 & -1 / 3 \\
-1 / 3 & -1 / 3 & 2 / 3
\end{array}\right] \cdot\left[\begin{array}{c}
V_{a o} \\
V_{b o} \\
V_{c o}
\end{array}\right]
$$

The line to line voltages are determined by the following equation:

$$
\left[\begin{array}{l}
V_{a b} \\
V_{b c} \\
V_{c a}
\end{array}\right]=\left[\begin{array}{ccc}
1 & -1 & 0 \\
0 & 1 & -1 \\
-1 & 0 & 1
\end{array}\right] \cdot\left[\begin{array}{c}
V_{a o} \\
V_{b o} \\
V_{c o}
\end{array}\right]
$$

\subsection{D-Q REFERENCE FRAME THEORY}

There are several methods to extract the harmonic components from the detected three-phase waveforms [18-19]. Among them, the so-called $\mathrm{p}$ - q theory based on time domain has been widely applied to the harmonic extraction circuit of active filters. The detected three-phase voltage is transformed into the D - Q coordinates as shown in Fig. 2. The second order digital high pass filters (HPFs) with the same cut off frequency as $17 \mathrm{~Hz}$ extract the dc component Vhd*, Vhq* and V0 which corresponds to the fundamental frequency in the coordinates.

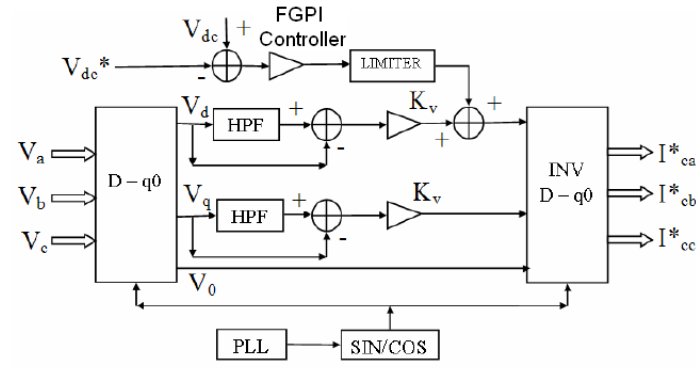

Fig.2. Block diagram of the control circuit equipped with the function of voltage regulation and harmonic damping or reduction.

In line - voltage regulation part is performed by a feedback control. Two co - ordinates $\mathrm{V}_{\mathrm{d}}$ and $\mathrm{V}_{\mathrm{q}}$ is compared with harmonic extracted voltage $\mathrm{V}_{\mathrm{hd}}{ }^{*}$ and $\mathrm{V}_{\mathrm{hq}}{ }^{*}$. A gain $\mathrm{K}_{\mathrm{V}}$ amplifies and to produce current references for harmonic damping $\mathrm{I}_{\mathrm{hd}}, \mathrm{I}_{\mathrm{hq}}$, and $I_{0}$ as shown in equation (7), equation (8) and equation (9). The current reference for the voltage - source inverter is the sum of the current references from the three parts, as follows:

$$
\begin{aligned}
& \mathrm{I}^{*}{ }^{*}(\mathrm{~s})=\mathrm{K}_{\mathrm{v}}\left(\mathrm{G}_{\mathrm{h}} \mathrm{V}_{\mathrm{hd}}{ }^{*}-\mathrm{V}_{\mathrm{d}}\right)+\left(\mathrm{V}_{\mathrm{dc}}{ }^{*}-\mathrm{V}_{\mathrm{dc}}\right) \text { or } \operatorname{ACE}(7) \\
& \mathrm{I}_{\mathrm{c}}^{*}(\mathrm{~s})=\mathrm{K}_{\mathrm{V}}\left(\mathrm{G}_{\mathrm{h}} \mathrm{V}_{\mathrm{hq}}{ }^{*}-\mathrm{V}_{\mathrm{q}}\right) \\
& \mathrm{I}^{*}{ }_{0}(\mathrm{~s})=1 / 3\left(\mathrm{~V}_{\mathrm{a}}+\mathrm{V}_{\mathrm{b}}+\mathrm{V}_{\mathrm{c}}\right)
\end{aligned}
$$

The obtained current reference is converted to three phase current reference by inverse $\mathrm{D}-\mathrm{Q}$ transformation $\mathrm{I}_{\mathrm{ca}}^{*}, \mathrm{I}_{\mathrm{cb}}^{*}$, and $\mathrm{I}^{*}{ }_{\mathrm{cc}}$. The three-three phase reference compensating current is compared with the DSTATCOM compensating current extracted from ac system. Thus three phase compensating current $\mathrm{I}_{\mathrm{ca}}, \mathrm{I}_{\mathrm{cb}}$, and $I_{c c}$ are produced. The obtained reference current is given to a fuzzy logic current controller in order to generate controlled gate signal for DSTATCOM.

\subsection{FGPI DC CAPACITOR VOLTAGE CONTROLLER FOR DSTATCOM}

Among the various available powers filter controllers PI, RST, hysteresis, adaptive control and fuzzy logic controller. In this application, the fuzzy gain scheduled PI control algorithm is implemented to control the DC capacitor inverter voltage based on DC voltage error in order to improve the dynamic performance of DSTATCOM.

Fuzzy set theory and fuzzy logic establish the rules of a nonlinear mapping [20]. The use of fuzzy sets provides a basis for a systematic way for the application of uncertain and indefinite models [21]. Fuzzy control is based on a logical system called fuzzy logic. It is much closer in spirit to human thinking and natural language than classical logical systems [22]. Nowadays, fuzzy logic is used in almost all sectors of industry, power systems and science. One of them is the harmonic current and reactive power compensation control [23]. The main goal of the harmonic current in DSTATCOM systems is to reduce and compensate the reactive power. Because of complexity and multi-variable conditions of the distributed power system, conventional control methods may not give satisfactory solutions. On the other hand, robustness and reliability make fuzzy controllers useful in solving wide range of control problems [23]. The fuzzy controller for the single input-output type of systems is shown in Fig. 3 [24]. 


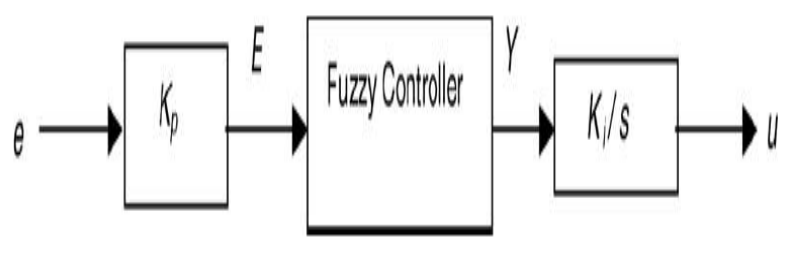

Fig. 3. Simple FGPI controller.

Table 2.FGPI controller rules.

\begin{tabular}{|l|l|l|l|l|l|l|l|}
\hline $\begin{array}{l}\text { ACE/ } \\
\text { ACE }\end{array}$ & LN & MN & SN & Z & SP & MP & LP \\
\hline LN & LP & LP & LP & MP & MP & SP & Z \\
\hline MN & LP & MP & MP & MP & SP & ZE & SN \\
\hline SN & LP & MP & SP & Z & Z & SN & MN \\
\hline Z & MP & MP & Z & SN & SN & MN & MN \\
\hline SP & MP & SP & Z & SN & SN & MN & LN \\
\hline MP & SP & Z & SN & MN & MN & MN & LN \\
\hline LP & Z & SN & MN & MN & LN & LN & LN \\
\hline
\end{tabular}

In this figure, $\mathrm{Kp}$ and $\mathrm{Ki}$ are the proportional and the integral gains, respectively. The fuzzy controller input can be derivative of $e$ together with signal E. The fuzzy controller block is formed by fuzzification of $\mathrm{E}$, inference mechanism and defuzzification. Therefore, $\mathrm{Y}$ is a crisp value and $u$ is a control signal for the system.

The DSTATCOM DC capacitor voltage which depend upon the actual control error $\left(\mathrm{V}_{\mathrm{dc}}{ }^{*}-\mathrm{V}_{\mathrm{dc}}\right.$ or ACE). By taking ACE as the system output, the control vectors for the conventional PI and I controllers, respectively can be given in the following forms:

$$
\begin{gathered}
u_{p i}(t)=-K_{p} A C E-\int K_{i}(A C E) d t \\
u_{i}(t)=-\int K_{i}(A C E) d t
\end{gathered}
$$

The simulation studies applied to the power systems are shown that the conventional controllers have large overshoots and long settling times [25]. Also, optimizing time for control parameters, especially PI controllers, is very long and the parameters are not calculating exactly. In addition, it has been known that conventional controllers generally do not work well for nonlinear, higher order and time-delayed linear, and particularly complex and vague systems that have no precise mathematical models [26]. According to many researchers, there are some reasons for the present popularity of fuzzy logic control. First, fuzzy logic can easily be applied to most industrial applications in industry. Second, it can deal with intrinsic uncertainties by changing controller parameters. Finally, it is appropriate for rapid applications. Therefore, fuzzy logic has been applied to the industrial systems as a controller. Human experts prepare linguistic descriptions as fuzzy rules, which are obtained based on step response experiments of the process, error signal, and its time derivative. Determining the controller parameters with these rules, a PI controller generates the control signal by which, the fuzzy gain scheduling proportional and integral controller (FGPI) is formed. Fuzzy logic shows experience and preference through membership functions, which have different shapes depending on the experience of system experts [27]. Same inference mechanism is realized by seven rules for the FGPI controller. The appropriate rules used in the study are given in Table 2.

$\mathrm{LN}$ : large negative; $\mathrm{MN}$ : medium negative; $\mathrm{SN}$ : small negative; Z: zero; SP: small positive; MP: medium positive; LP: large positive, ACE; actual control error or actual control dc voltage error, $\triangle \mathrm{ACE}$; change in actual control error or change in actual control dc voltage error.

The membership function sets of FGPI controller for ACE, $\Delta$ $\mathrm{ACE}, \mathrm{Kp}$ and $\mathrm{Ki}$ are shown in Fig. 4. Defuzzification has also been performed by the center of gravity method in these studies. A critical issue in this DSTATCOM is the dc-bus voltage control. The dc bus consists of a single capacitor charged from the power supply. During operation, the DSTATCOM may absorb an amount of active power into, or release it from, the dc capacitor. Excessive active power absorption will increase the dc-bus voltage, and may damage the DSTATCOM.

The strategy used to control the dc-capacitor voltage is based on DSTATCOM control. According to the D - Q theory, a dc component in the $\mathrm{D}-\mathrm{Q}$ coordinates corresponds to active power. No direct axis current on the $\mathrm{D}-\mathrm{Q}$ coordinates flows in the filter. Thus, the active power is controlled by adjusting the quadrature axis component. The direct axis is set to zero. Fig. 3 shows a block diagram of the FGPI dc capacitor voltage control for DSTATCOM. The dc-capacitor voltage is detected and compared with a reference, amplifying the error signal by a control gain signal. A limiter is included in the FGPI dccapacitor voltage control loop. It is designed to ensure a smooth transient response and to avoid sudden increments or decrements in the dc-capacitor voltage.

(a)

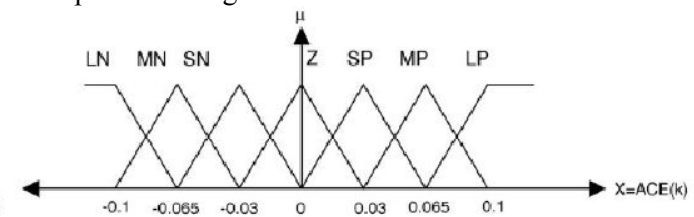

(b)

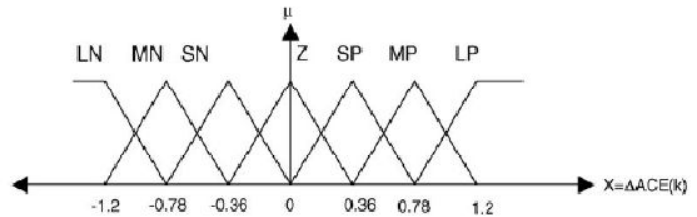

(c)

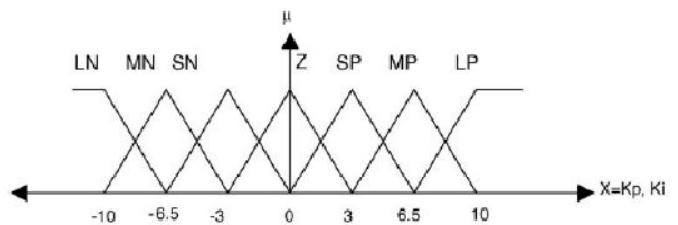

Fig. 4. Membership functions for FGPI Controller of (a) ACE, (b) $\triangle \mathrm{ACE}$, (c) Kp, Ki.

\subsection{FUZZY CURRENT CONTROL SCHEME AND PWM METHOD FOR DSTATCOM}

The control technique implements a fuzzy logic current controller which starts from the difference between the injected current (DSTATCOM current) and reference current 
(identified current) that determines the reference voltage of the inverter (modulating reference signal). This standard reference voltage is compared with two carrying triangular identical waves shifted one from other by a half period of chopping as shown in Fig. 5.

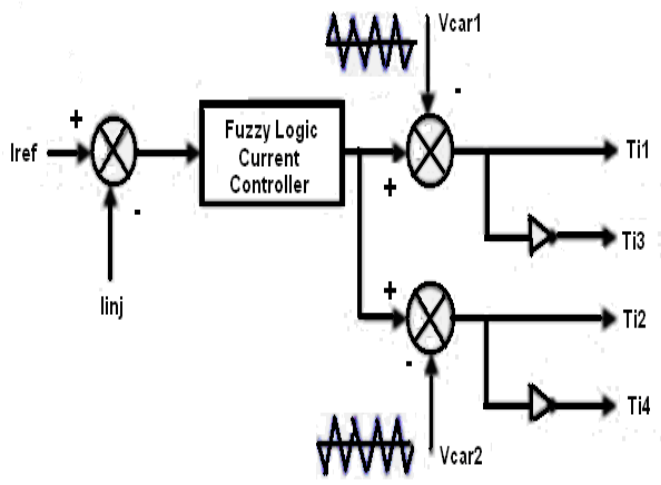

Fig.5. PWM generation block diagram of fuzzy logic currents control.

The control of inverter arm constituting the filter is summarized in the two following stages.

- Determination of the intermediate signals $\mathrm{V}_{\mathrm{i} 1}$ and $\mathrm{V}_{\mathrm{i} 2}$.

$$
\begin{aligned}
& \text { If error } \geq \text { carrying } 1 \Rightarrow \mathrm{V}_{\mathrm{i} 1}=1 . \\
& \text { If error }<\text { carrying } 1 \Rightarrow \mathrm{V}_{\mathrm{i} 1}=0 . \\
& \text { If error } \geq \text { carrying } 2 \Rightarrow \mathrm{V}_{\mathrm{i} 2}=0 . \\
& \text { If error }<\text { carrying } 2 \Rightarrow \mathrm{V}_{\mathrm{i} 2}=-1 .
\end{aligned}
$$

- Determination of control signals of the switches $T_{i j} \quad(j=1$, $2,3,4)$.

$$
\begin{aligned}
& \text { If }\left(\mathrm{V}_{\mathrm{i} 1}+\mathrm{V}_{\mathrm{i} 2}\right)=1 \Rightarrow \mathrm{T}_{\mathrm{i} 1}=1, \mathrm{~T}_{\mathrm{i} 2}=1, \mathrm{~T}_{\mathrm{i} 3}=0, \mathrm{~T}_{\mathrm{i} 4}=0 . \\
& \text { If }\left(\mathrm{V}_{\mathrm{i} 1}+\mathrm{V}_{\mathrm{i} 2}\right)=0 \Rightarrow \mathrm{T}_{\mathrm{i} 1}=0, \mathrm{~T}_{\mathrm{i} 2}=1, \mathrm{~T}_{\mathrm{i} 3}=1, \mathrm{~T}_{\mathrm{i} 4}=0 . \\
& \text { If }\left(\mathrm{V}_{\mathrm{i} 1}+\mathrm{V}_{\mathrm{i} 2}\right)=-1 \Rightarrow \mathrm{T}_{\mathrm{i} 1}=0, \mathrm{~T}_{\mathrm{i} 2}=0, \mathrm{~T}_{\mathrm{i} 3}=1, \mathrm{~T}_{\mathrm{i} 4}=1 .
\end{aligned}
$$

General block diagram of fuzzy logic currents control is illustrated in Fig. 5.

Fig. 5 shows the structure of the fuzzy logic current controller, which has two inputs and one output. The inputs are namely error (e), which is the difference between the reference current and DSTATCOM currents $\left(e=i_{\text {ref }}-i_{f}\right)$ and change in error, which is the derivation of error (de) while the output is the command signal (cde).

The aim is to get the sinusoidal source currents in phase with supply voltages. This step consists on replacing the conventional controllers by fuzzy logic controllers characteristics of the fuzzy control used in this work are:

- Five fuzzy sets for each input (e, de) with Gaussian membership functions,

- Five fuzzy sets for the output with triangular membership functions,

- Implications using the 'minimum operator', inference mechanism based on fuzzy implication containing five fuzzy rules,

- Defuzzyfication using the 'centroid' method.

The establishment of the fuzzy rules is based on the error (e) sign, variation and knowing that (e) is increasing if its derivative (de) is positive, constant if (de) is equal to zero, decreasing if (de) is negative, positive if $\left(i_{r e f}>i_{f}\right)$, zero if $\left(i_{\text {ref }}\right.$ $\left.=i_{f}\right)$, and negative if $\left(i_{r e f}<i_{f}\right)$, fuzzy rules are summarized as following:
- If (e) is zero (Z), then (cde) is zero (Z).

- If (e) is positive (P), then (cde) is big positive (BP).

- If (e) is negative $(N)$, then (cde) is big negative (BN).

- If (e) is zero ( $\mathrm{Z}$ ) and (de) is positive (P), then (cde) is negative $(\mathrm{N})$.

- If (e) is zero ( $\mathrm{Z})$ and (de) is negative $(\mathrm{N})$, then (cde) is positive $(\mathrm{P})$

\section{SIMULATION STUDY}

The designed FGPI and fuzzy current controller have been tested on a distorted wave produced by a diode bridge rectifier with RL load and three-level PWM inverter used as DSTATCOM. The validation of the system performance is done for steady state region. The simulations have been performed on the DSTATCOM with parameters are listed in Table 3.

The performances of DSTATCOM with proposed control schemes are evaluated in Matlab/Simulink software platform. The Matlab/Simulink simulation model of proposed system with control methods are depicted in Fig. 6 .

Table 3. Simulation parameters of DSTATCOM.

\begin{tabular}{|c|c|c|}
\hline Supply & Vs, Rs, Ls & $220 \mathrm{~V}, 0.01 \mathrm{ohm}, 0.3 \mathrm{mH}$ \\
\hline DC load & Rdc, Ldc & $50 \mathrm{ohm}, 0.1 \mathrm{mH}$ \\
\hline DSTATCOM & $\begin{array}{c}\text { Vdc, Lf, } \\
\text { C1=C2 }\end{array}$ & $1000 \mathrm{~V}, 3 \mathrm{mH}, 1000 \mu \mathrm{F}$ \\
\hline $\begin{array}{c}\text { Switching and } \\
\text { supply } \\
\text { frequency }\end{array}$ & Fs & $10 \mathrm{kHz}$ and $50 \mathrm{~Hz}$ \\
\hline
\end{tabular}

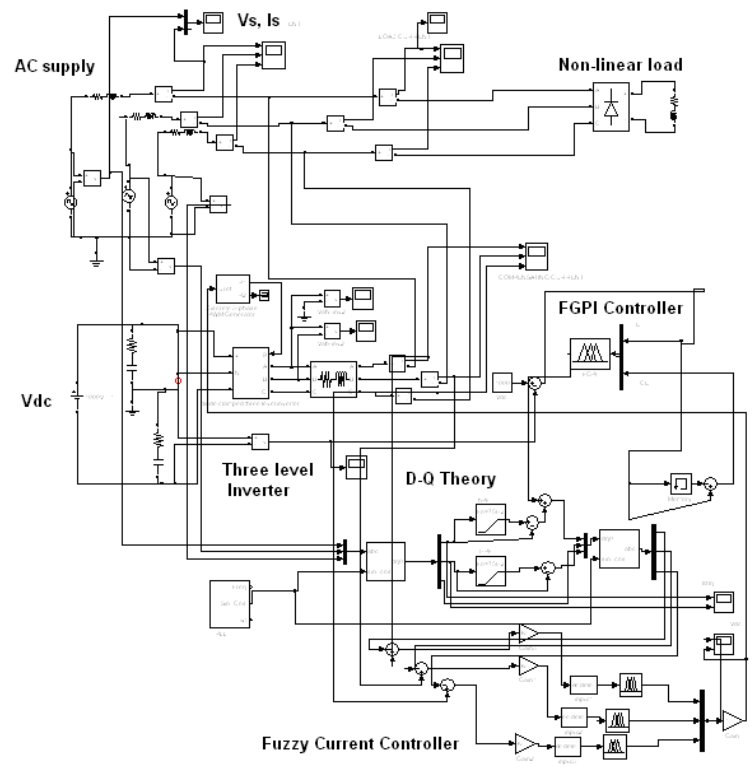

Fig. 6. Simulation model of DSTATCOM with proposed controllers. 


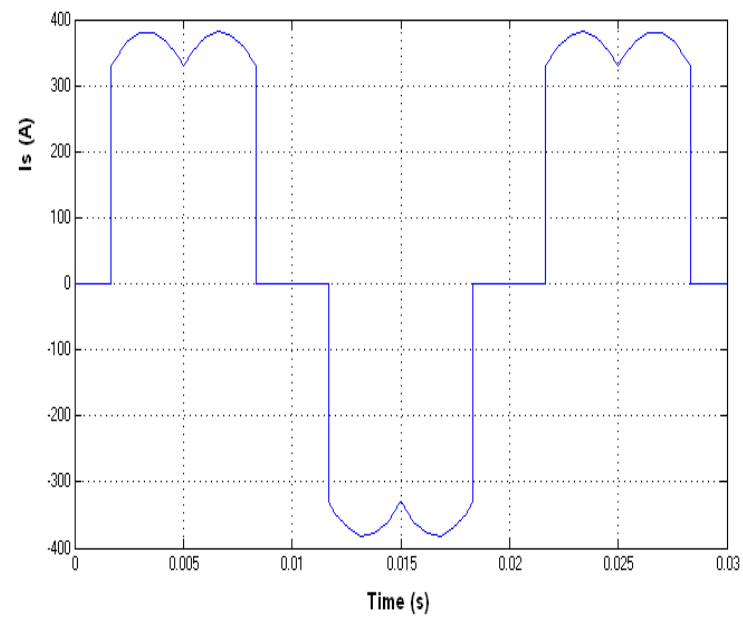

Fig. 7. Source current without DSTATCOM.

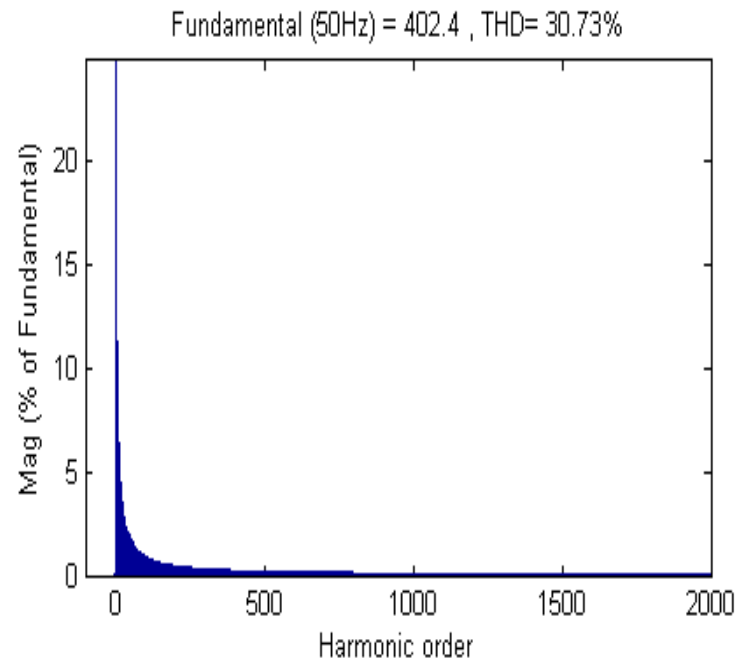

Fig. 8. Total harmonic distortion (THD) for Source current without DSTATCOM.

The source current obtained without DSTATCOM is illustrated in Fig. 7. This current is highly distorted and

Its THD calculated from the frequency spectrum shown in Fig. 8 is equal to $30.73 \%$.
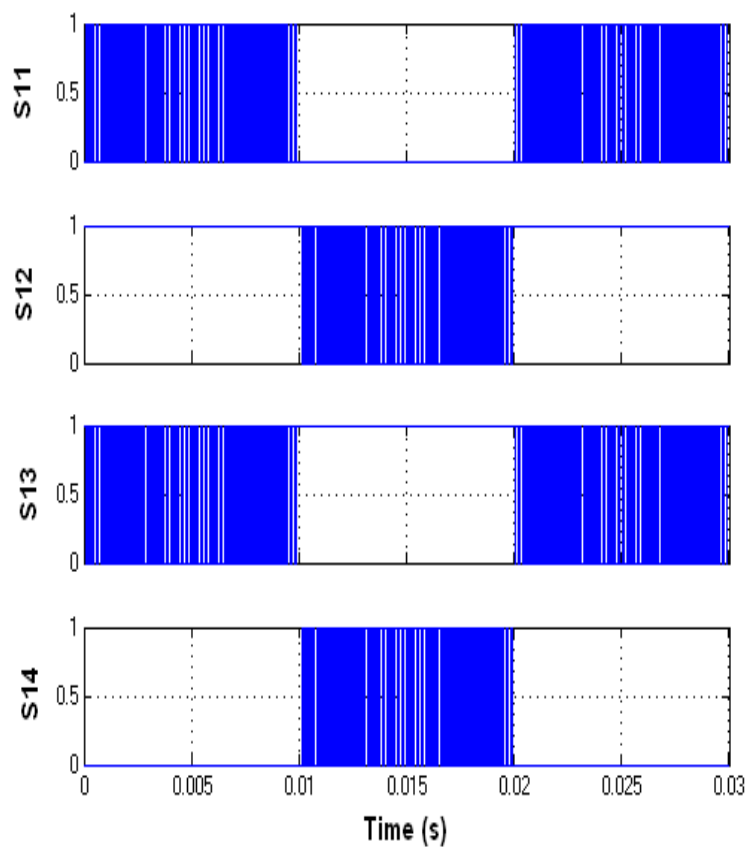

Fig. 9. Switching pulses of DSTATCOM arms (S11, S12, S13 and S14).

The obtained switching signals of the three-phase three-level inverter are shown in Fig. 9.

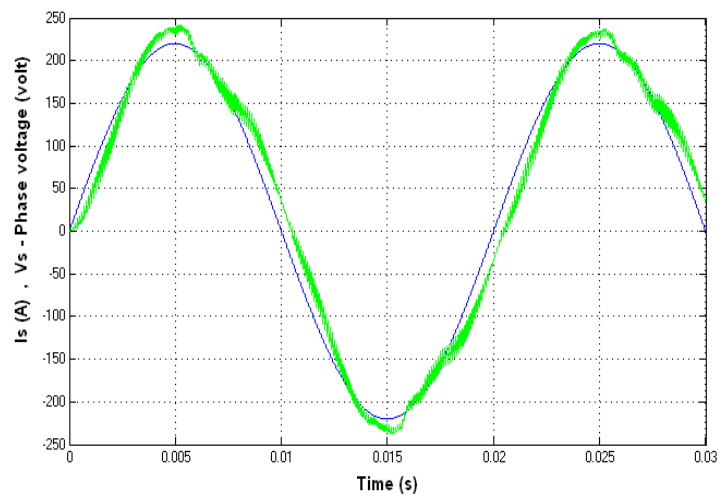

Fig. 10. Source current and source voltage with DSTATCOM.

Three-level DSTATCOM performances are related to current references quality, D-Q theory is used for harmonic currents identification and calculation, the obtain current. This control method is very important; it allows harmonic currents and reactive power compensation simultaneously, the obtained current and voltage waveforms are in phase as illustrated in Fig. 10. 


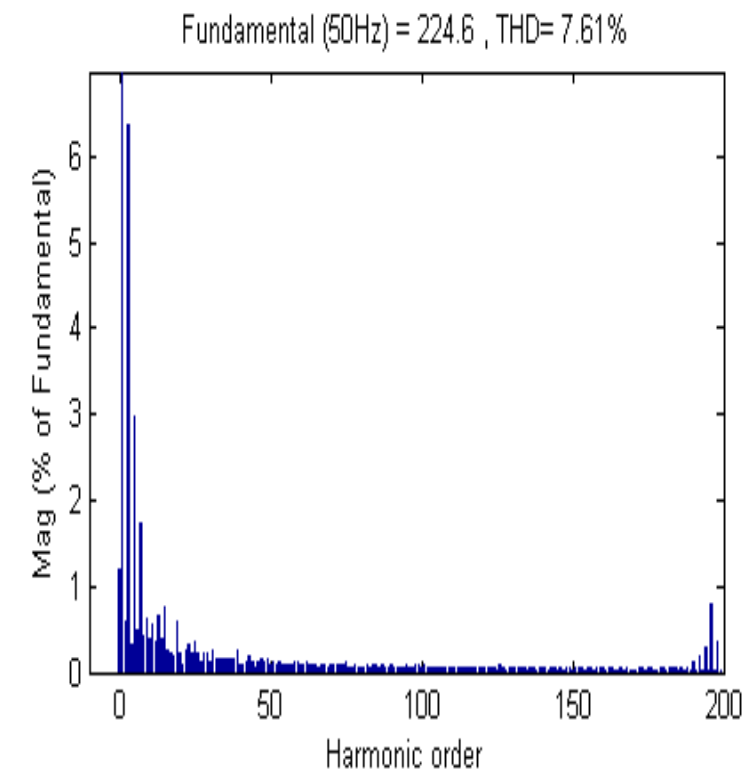

Fig. 11. Total harmonic distortion for Source current with DSTATCOM.

From Fig. 11, it can be concluded that three levels DSTATCOM contains less harmonic with a THD of the source current equal to $7.61 \%$ with DSTATCOM.

The three-level output voltages $\mathrm{V}_{\mathrm{ao}}$ and $\mathrm{V}_{\mathrm{ab}}$ are shown in Figs. 12 and 13.

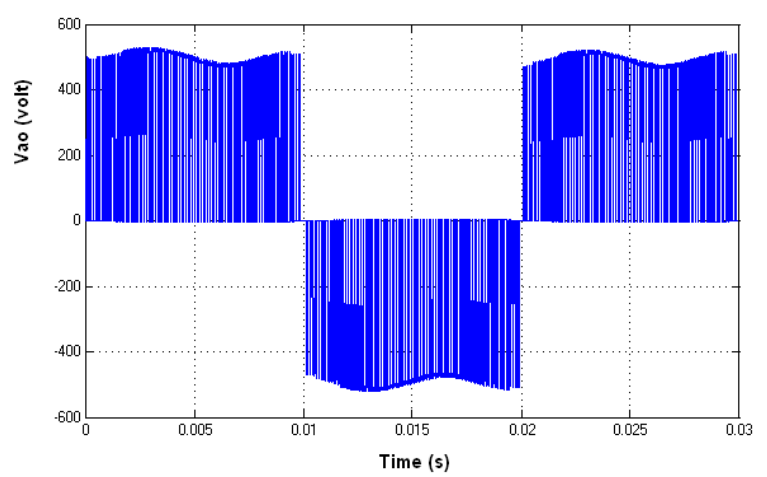

Fig. 12. DSTATCOM output voltage Vao.

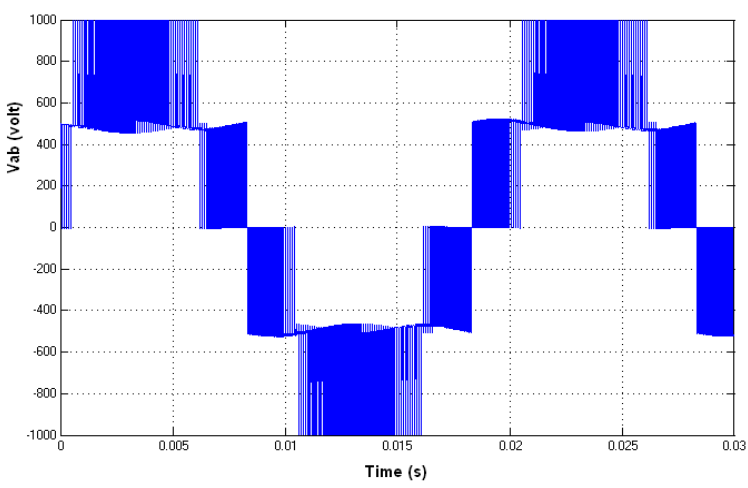

Fig. 13. DSTATCOM output voltage Vab.

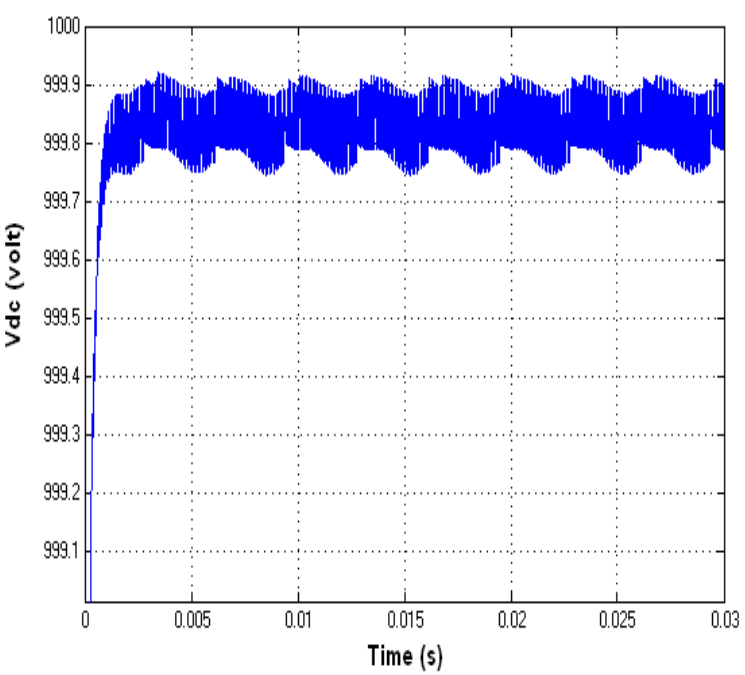

Fig. 14. DC voltage of capacitors ( $\mathrm{Vdc})$.

In Fig. 14 shows the constant and small ripple dc capacitor voltage without startup-transient overshoot.

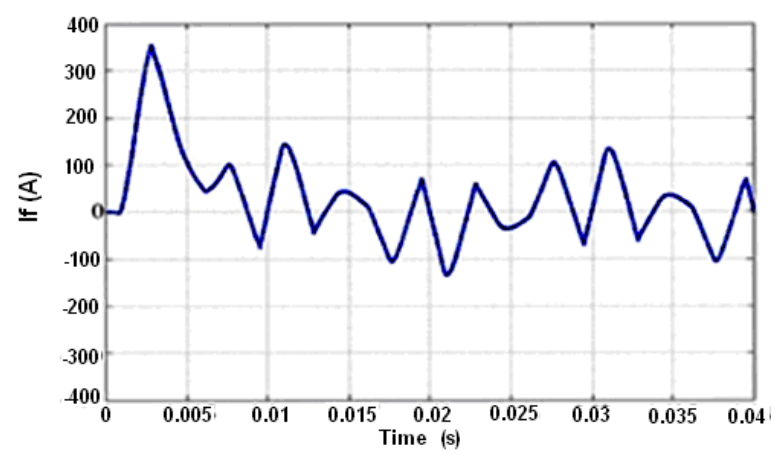

Fig. 15. DSTATCOM compensated current (If).

In Fig. 15 shows the compensated current of DSTATCOM with designed controllers.

\section{CONCLUSIONS}

In this paper theoretical study with simulation of a FGPI and fuzzy logic controllers for a three- level DSTATCOM based on D-Q theory to identify reference currents and PWM method to generate switching signals have shown high DSTATCOM performances in reducing harmonics, and power factor correction. The obtained simulation results show that DC capacitor voltage and the harmonic currents control are very important. With proposed control schemes, the DSTATCOM can be adapted easily to other more severe constraints, such as unbalanced conditions. The three-level DSTATCOM for the three-phase circuit is simulated and the THD measured verifies the reduction of harmonics to a very low level when the FGPI and fuzzy logic controllers were employed. The three-level DSTATCOM provides many advantages such as improvement of the supply current waveform, less harmonic distortion and its use in high power/medium voltage with a lower maximum device rating. 


\section{REFERENCES}

[1] J. S Lai and F. Z. Peng, Multilevel converters-A new breed of power converters, IEEE Trans. Industry Applications, vol.32, no.3, pp. 509-517, May/June. 1996.

[2] F. Z. Peng., J. W. McKeever and, D .J. Adams, A power line conditioner using cascade multilevel inverters for distribution system, IEEE Trans. Industry Applications, vol.34, no.6, pp. 1293-1298, Nov.-Dec.1998.

[3] W. Liqiao, L. Ping, L. Jianlin and Z. Zhongchao, Study on shunt active power filter based on cascaded multilevel converters, 35th IEEE Power Electr. Spec. Conf. (APEC), vol.5, pp. 3512-3516, 20-25 June 2004.

[4] M. P. Kazmierkowski and L. Malesani, Current control techniques for three-phase voltage-source PWM converters: A survey, IEEE Trans Industrial Electronics, vol.45, no.5, pp. 691-703, Oct. 1998.

[5] A. Ghosh and G. Ledwich, Power Quality Enhancement using Custom Power Devices, Kluwer Academic Publisher, Boston, MA, 2002.

[6] A. Ghosh and G. Ledwich, Load Compensating DSTATCOM in weak AC systems, IEEE Trans. Power Delivery, vol. 18, No. 4, pp. 1302-1309, Oct. 2003.

[7] G. Ledwich and A. Ghosh, A flexible DSTATCOM operating in voltage or current control mode, IEE Proc. Generation, Trans. \& Distrib.,vol. 149, No. 2, pp,

224, March 2002.

[8] A. Dell'Aquila, G. Delvino, M. Liserre, P. Zancheta, A new fuzzy logic strategy for active power filter, power electronics and variable speed drives, 18-19 September 2000, Conference Publication No. 475, pp. 392-397.

[9] S.K. Jain, P. Agrawal, H.O. Gupta, Fuzzy controlled shunt active filter for quality improvement, IEEE. Pro. Electr. Power Appl. 149 (September (5))(2002)317-328.

[10] C. Charmeela, M.R. Mohan, G. Uma, J. Baskaran, Fuzzy logic controller based three-phase shunt active filter for line harmonics reduction, J. Comput. Sci. 3(2) (2007)7680 (ISSN 1549-3636).

[11] S. Saad, L. Zellouma, L. Herous, Comparison of fuzzy logic and proportional controller of shunt active filter compensating current harmonics and power factor, in: Proceedings of the 2nd International conference on Electrical EngineeringDesign and Technology ICEEDT08, Hammamet, Tunisia, November 8-10, 2008.

[12] L. Zellouma, S. Saad, Fuzzy logic controller for three phase shunt active filter compensating harmonics and reactive power simultaneously, in: Proceedings of the International Conference on Computer Integrated Manufacturing CIP', Setif, Algeria, 03-04 November, 2007.

[13] H. Unbehauen, U. Keuchel, I. Kocaarslan, Real-time adaptive control of electrical power and enthalpy for a $\quad 750$ MW once-through boiler, vol. 1, in: Proceedings of IEE International Control Conference 91, Edinburg, Scotland, 25-28 March, 1991, pp. 42-47.
[14] Stefan Sprenga, Harald Weberb, Matthias Hladky, Investigation of the dynamic behaviour of hydro power plants for restoration scenarios, Electr. Power Energ. Syst. 25 (2003) 615-621.

[15] C.S. Chang, Weihui $\mathrm{Fu}$, Area load-frequency control using fuzzy gain scheduling of PI controllers, Electr. Power Syst. Res. 42 (1997) 145-152.

[16] I. Kocaarslan, G. Akalın, T. Erfidan, Application of fuzzy reasoning to load-frequency control in two-area power system, in: Proceedings of European Control Conference ECC'99, Karlsruhe, Germany, 31August-3 September 1999, pp. 27-31.

[17] X.Y. Li, O.P. Malik, Control scheme for emergency state control of interconnected power systems with multistage recursive least-squares identification, Int. J. Electr. Power Energ. Syst. 16 (2) (1994) 97-103.

[18] H. Akagi, Y. Kanazawa, A. Nabae, Generalized theory of the instantaneous reactive power in three-phase circuits, in: Proceedings of the 1985 International Power Electronics Conference, Tokyo, Japan, 1985, pp. 1375-1386.

[19] M. Gaiceau, Active power compensator of the current harmonics based on the instantaneous power Theory, The annals of "dunarea de jos" University of Galati FASCLE III. ISSN 1221-454 005, pp. 23-28.

[20] J.M. Mendel, Fuzzy logic systems for engineering: a tutorial, Proc.IEEE 83 (3) (1995) 345-377.

[21] C.C. Lee, Fuzzy logic in control systems: fuzzy logic controller-part I, IEEE Trans. Syst. Man Cybern. 20 (1990) 404-418.

[22] C.C. Lee, Fuzzy logic in control systems: fuzzy logic controller-part II, IEEE Trans. Syst. Man Cybern. 20 (1990) 419-435.

[23] S. Tesnjak, S. Mikus, O. Kuljaca, Load-frequency fuzzy control in power systems, in: Proceedings of the Fifth SONT, Simpozijo Novim Tehnologijima, Poree, 1995, pp. 136-139.

[24] T. Tilli, Automatisierung Mit Fuzzy-Logic, FranzisVerlag, Munchen, 1992.

[25] A. Kumar, O.P. Malik, G.S. Hope, Variable structuresystem control applied to AGC of an interconnected power system, IEE Proc. 132 (Pt. C, no. 1) (1985) 23- 29.

[26] K.S. Tang, K.F. Man, G. Chen, S. Kwong, An optimal fuzzy PID controller, IEEE Trans. Ind. Electron. 48 (4) (2001) 757-765.

[26] K. Tomsovic, in: Proceedings of International Conference on Intelligent System Application to Power Systems, Fuzzy Syst. Appl. Power Syst., IRio de Janeiro, Brazil, April 1999, pp. 1-10 (ChapterIV-short course). 